\title{
Pregnancy, systemic lupus erythematosus and a short communication on labor complications as new onset of the disease
}

\author{
Anca Angela Simionescu ${ }^{1,2}$, Sanziana Daia-lliescu ${ }^{3,4}$ \\ ${ }^{1}$ Department of Obstetrics and Gynecology, "Carol Davila" University of Medicine and Pharmacy, \\ Bucharest, Romania \\ 2 Filantropia Clinical Hospital, Bucharest, Romania \\ ${ }^{3}$ Department of Internal Medicine and Rheumatology, "Carol Davila" University of Medicine and Pharmacy, \\ Bucharest, Romania \\ 4"Sf. Maria" Hospital, Bucharest, Romania
}

\begin{abstract}
Systemic lupus erythematosus (SLE) occur frequently in women of fertile age. In the pathogenesis of SLE, estrogen plays an important role, hormonal changes such as pregnancy and the postpartum increase the risk of disease flares. Also, pregnancy in SLE patients carries a higher fetal risk compared with healthy women. Pregnancy outcome may be optimized by careful planning of the pregnancy and close follow-up of the mother and of the fetus. SLE is associated with high maternal and fetal risk especially when non-diagnosed before planning a pregnancy. Herein we present two cases of SLE manifested by preeclampsia and acute renal insufficiency during labor and postpartum period, with a difficult diagnosis after a few months of a worsening clinical situation.
\end{abstract}

Keywords: systemic lupus erythematosus, nephritis, preeclampsia, pregnancy

\section{INTRODUCTION}

Systemic lupus erythematosus (SLE) is a chronic, multisystemic disease that predominantly affects women in their fertile age. SLE associated pregnancy is at increased risk for maternal and fetal outcomes. Fetal complication includes congenital heart block when anti-Ro/SSA and anti-La/SSB antibodies are present, prematurity, intrauterine growth restriction, stillbirth and neonatal lupus. Maternal complications include gestational hypertension, lupus nephritis and preeclampsia (1-3). During pregnancy, SLE is presumed to be more aggressive and to portend a worse prognosis than non-pregnancy SLE. This may be explained by higher disease activity during pregnancy, especially when active disease within 6 months before conception, discontinuation of hydroxychloroquine, more lupus nephritis and neuropsychiatric lu- pus (3-5). When the diagnosis of SLE is established before the occurrence of a pregnancy, pre-conception counselling about the optimal time for conception, and establishing optimal treatment should reduce the rate of maternal and fetal complications. Among rheumatic diseases, it appears that SLE pregnancies were the most frequently associated with maternal and fetal complications when comparing with pregnancies in patients with rheumatoid arthritis (6).

\section{PHYSIOLOGICAL CHANGES IN PREGNANCY}

Hormonal and immune changes occur during pregnancy in order to allow the immunogenic allograft, the fetus, to grow. Cytokines are important mediators and pregnancy used to be considered a "Th2 phenomenon": Th2 lymphocytes play a protective 
role and counteract pregnancy pathology such as fetal growth restriction, fetal death and eclampsia; nowadays, the concept of "Th1/Th2 paradigm" defines the shift of Th1 to Th2 immune response, as the successful pregnancy is dependent on Th2 cytokines while spontaneous abortion is associated with a Th1 cytokine-pattern.

Currently, it is considered that humoral and cellular immunity are involved together in the homeostasis of pregnancy, the cytokines and their role varying with the different stages of pregnancy. For example, in early pregnancy, the Th1 cytokines, IFN gamma and TNF alpha, play their role in the implantation and development of the placenta, but towards the end of pregnancy, the same molecules may favor pregnancy loss (7). Hormonal changes lead to the switching of the Th1 immune response to Th2, inducing tolerance of the pregnancy, an allograft with paternal antigens, but hormonal changes have an impact also on the autoimmune condition in the mother (8).

\section{SLE AND PREGNANCY OUTCOME}

Several rheumatic immune-mediated diseases are influenced by pregnancy or by the postpartum period. In autoimmune diseases in which the Th 1 cellular response is predominant, the involvement of the Th2 immune response will lead to the amelioration of the disease.

Diseases with B lymphocyte hyperreactivity and autoantibody production, like SLE, have an increased risk of flare or of pregnancy complications.

Hypercoagulability or the presence of antiphospholipid antibodies (PLA) adds to the risk. Several mechanisms are known in the pathogenesis of antiphospholipid syndrome (APS): prothrombotic, proinflammatory, angiogenetic and sometimes the low efficiency of the antithrombotic therapy. In addition to the thrombotic mechanism (thrombosis and placental infarction), other non-thrombotic, inflammatory mechanisms induced by B2GP1 interfere with trophoblast growth and implantation. B2GP1 also binds directly to the trophoblast interfering with its differentiation and functions; The final effect is the destruction of the trophoblast and the loss of pregnancy (9).

Among the antibodies that cross the placenta, anti-SS-A (anti Ro) and anti SS-B (anti La) antibodies may induce neonatal lupus. Autoimmune-mediated congenital heart block is the most common manifestation of cardiac neonatal lupus (10).
TABLE 1. Maternal and fetal complications in patients with SLE and APS (3)

\begin{tabular}{|c|c|c|c|}
\hline $\begin{array}{l}\text { Rheumatic } \\
\text { disease }\end{array}$ & $\begin{array}{l}\text { Maternal } \\
\text { complications }\end{array}$ & $\begin{array}{l}\text { Foetal } \\
\text { complications }\end{array}$ & Risk factors \\
\hline SLE & $\begin{array}{l}\text { Impaired fertility- } \\
\text { CFM } \\
\text { Active disease } \\
\text { (in vitro } \\
\text { fertilisation), } \\
\text { pregnancy, } \\
\text { postpartum) } \\
\text { High blood } \\
\text { pressure, } \\
\text { preeclampsia } \\
\text { HELLP } \\
\text { caesarean }\end{array}$ & $\begin{array}{l}\text { Neonatal } \\
\text { lupus } \\
\text { Cardiac } \\
\text { congenital } \\
\text { block } \\
\text { Intrauterine } \\
\text { growth } \\
\text { restriction } \\
\text { Pregnancy } \\
\text { loss } \\
\text { Premature } \\
\text { birth }\end{array}$ & $\begin{array}{l}\text { Active disease } \\
\text { at time of } \\
\text { conception or } \\
\text { pregnancy } \\
\text { Active lupus } \\
\text { nephritis } \\
\text { High blood } \\
\text { pressure } \\
\text { APS } \\
\text { ac anti Ro ab, } \\
\text { ac anti La ab }\end{array}$ \\
\hline APS & $\begin{array}{l}\text { Thrombosis } \\
\text { (peripartum) } \\
\text { Pre-eclampsia } \\
\text { Eclampsia } \\
\text { HELLP } \\
\text { Thrombocyto- } \\
\text { penia }\end{array}$ & $\begin{array}{l}\text { Intrauterine } \\
\text { growth } \\
\text { restriction } \\
\text { Pregnancy } \\
\text { loss } \\
\text { Premature } \\
\text { birth } \\
\text { Thrombosis in } \\
\text { the neonate } \\
\text { (seldom) }\end{array}$ & $\begin{array}{l}\text { Triple Ab } \\
\text { positivity }\end{array}$ \\
\hline
\end{tabular}

Data from recent clinical trials show a significant decrease in pregnancy complications, including mortality in patients with SLE (3).

Patients with SLE have a higher risk of obstetric complications with an impact on both the fetus and the mother (table 1) (3).These include: premature birth, fetal growth restriction, pregnancy loss, stillbirth, neonatal lupus and complications of prematurity, preeclampsia and eclampsia (11). Patients also have an increased risk of thrombosis, infection, thrombocytopenia, gestational diabetes or transfusions, and also maternal mortality is higher (12).

Predictive factors of fetal complications are partly common with those predictive of disease complications: active disease (disease activity 6-12 months before conception, especially renal, hypocomplementemia, anti-dsDNA antibodies), history of renal flare, the need for antihypertensive medication, primigravida, antiphospholipid antibodies - risk of miscarriage, anti-Ro and anti La antibodies-risk of neonatal lupus, thrombocytopenia, corticotherapy in high doses, immunosuppressants $(1,13,14)$.

\section{COMPLICATIONS}

The most common obstetric complication is premature birth; nephritis and active disease are high predictors of this complication (15).

The risk of miscarriage is increased in all three trimesters. 
Placental insufficiency is common in SLE. As a consequence, intrauterine growth restriction or fetal death in the third trimester or intrapartum may be encountered.

Association with anti-Ro and La may also add to the risk so the presence of anti-Ro and anti-La antibodies should be evaluated before conception or as early as possible in pregnancy, in patients with SLE, Sjögren's syndrome or in mothers who already have a child with neonatal lupus or congenital atrioventricular block, or in pregnant women with fetal bradycardia or atrioventricular block on fetal echocardiography (16).

\section{Neonatal lupus}

Neonatal lupus is an acquired autoimmune condition due to the passive transfer of antibodies from mother to the fetus. Anti-Ro and anti La antibodies cross the placenta starting with the 11th week of gestation and cardiac changes may be detected in 18th26th week of intrauterine life (13).

The main manifestations are cutaneous and cardiac. Congenital heart block (CHB) is characteristic for the cardiac SLE. Skin manifestations - malar rash, transient cytopenias, high liver enzymes do not last long after birth and remit spontaneously with the disappearance of antibodies from the mother.

Close monitoring of fetal cardiac activity is recommended starting with the 16th and 18th week of pregnancy. The ACR recommends weekly echocardiographic monitoring until week 26 , especially in patients with a history of newborns with total heart block $(10,17)$.

Regarding the treatment of the fetal cardiac manifestations, hydroxychloroquine is recommended throughout pregnancy and when echocardiography indicates grade I or II cardiac block, dexamethasone $4 \mathrm{mg}$ / day may be added; in case of total heart block (without cardiac inflammation), the treatment with dexamethasone is not advised $(8,10,17)$.

\section{Antiphospholipid syndrome}

Primary or secondary APS is associated with thrombotic events or obstetric pathology. The presence of antiphospholipid antibodies (PLA) is an independent risk factor for miscarriage.

Pregnancy morbidity consists of recurrent miscarriages, fetal death after 10 weeks of pregnancy and premature birth before 34 weeks of pregnancy due to preeclampsia / eclampsia or placental insufficiency leading to fetal growth restriction (18).
The high-risk profile of thrombosis/obstetrical events is represented by lupus anticoagulant positive at least twice, at twelve weeks apart, or double or triple antibody positivity (lupus anticoagulant, anticardiolipin Ab and aB2GPI) or persistently high aPL titer; low risk profile means the presence of aCL or anti b2GP1 in low / medium titer; additional risk factors may be represented by history of APS events.

In all patients with SLE, it is recommended to evaluate the presence of antiphospholipid antibodies before pregnancy or early pregnancy. Among them, lupus anticoagulant has the highest risk of fetal loss in women with or without SLE (17).

EULAR recommendations for the management of APS in pregnancy are differentiated according to the risk and individual factors (8).

\section{THE IMPACT OF PREGNANCY ON SLE}

Pregnancy in patients with SLE is associated with high fetal and maternal risk. During pregnancy and the postpartum period there is an increased risk of disease flares $(19,20)$, especially renal or hematological flares $(19,21), 6$ and less often musculoskeletal flares. Exacerbations occur more frequently in the second trimester of pregnancy compared to the third, most are of medium-moderate intensity and rarely severe requiring modification of the therapeutic regimen $(1,22,23)$.

Factors associated with an increased risk of disease activity during pregnancy are: non-white race, young age, first pregnancy, active disease before or at conception, history of renal impairment or discontinuation of hydroxychloroquine treatment during pregnancy. However, even in patients with some of the listed risk factors, the exacerbation rate is low if the pregnancy is well planned $(12,22)$.

In the pathogenesis of SLE, estrogen plays an important role, being involved in increasing the survival of $\mathrm{T}$ and $\mathrm{B}$ lymphocytes and also in the production of antibodies by the B lymphocytes. Variations of the estrogen (induced by oral contraceptives or associated with pregnancy and postpartum) increase the risk of disease flare, menopause favoring the remission of the disease $(8,24)$.

Assessment of SLE disease activity is done with several pregnancy-adapted indices, derived from the usual SLE activity assessment tools: SLEPDAI (SLE Pregnancy Disease Activity Index), LAI-P (Lupus activity index in pregnancy) or SLAM (Systemic Lupus Activity Measure).). The SLEPDAI score is the SELENA -SLEDAI score adapted to exclude signs 
and symptoms specific to pregnancy that could mimic the activity of the disease (chloasma, headache etc.) $(8,25)$.

During pregnancy, it is very challenging to diagnose for the first time the disease flare in lupus because pregnancy may induce malar rash and palmar erythema or exacerbation of acne and facial flush which resemble of the sign of SLE (Table 2).

TABLE 2. Differential diagnosis of common features of active SLE and pregnancy - adapted from $(8,19)$

\begin{tabular}{|l|l|l|}
\hline Features & Related to pregnancy & Related to SLE flare \\
\hline Anaemia & $\begin{array}{l}\text { haemodilution } \\
\text { iron deficiency }\end{array}$ & $\begin{array}{l}\text { haemolytic } \\
\text { chronic disease }\end{array}$ \\
\hline Proteinuria & preeclampsia & Renal flare \\
\hline $\begin{array}{l}\text { arthritis/ } \\
\text { arthralgia }\end{array}$ & Mechanic & $\begin{array}{l}\text { Inflammatory- } \\
\text { synovitis }\end{array}$ \\
\hline $\begin{array}{l}\text { Thrombocyto- } \\
\text { penia }\end{array}$ & Gestational & $\begin{array}{l}\text { Immune } \\
\text { thrombocytopenia }\end{array}$ \\
\hline & HELLP & APS \\
\hline rash & preeclampsia & Malar rash \\
\hline Seizure & chloasma/ erythema & $\begin{array}{l}\text { Neurologic } \\
\text { involvement } \\
\text { thrombosis }\end{array}$ \\
\hline
\end{tabular}

Careful differentiation should be made between disease activity and preeclampsia or HELLP syndrome. HELLP syndrome is defined by the triad: hemolysis (microangiopathic hemolytic anemia), elevated liver enzymes and low platelets. Pre-eclampsia (26) is defined by the American College of Obstetrics and Gynecology guidelines, as hypertension that develops after 20 weeks of pregnancy or during the postpartum period $(\mathrm{BP}>140 \mathrm{mmHg}$ systolic or $\mathrm{BP}>90 \mathrm{mmHg}$ diastolic in two separate readings or $\mathrm{BP}>160 \mathrm{mmHg} / 110 \mathrm{mmHg}$ ) and proteinuria (300 $\mathrm{mg} / 24 \mathrm{~h}$ or protein/creatinine index $>0.3$ ) or HELLP syndrome - low platelets, kidney or liver involvement, neurological or visual symptoms. Differential diagnosis between lupus nephritis and preeclampsia is shown in table 3.

Differentiating between preeclampsia/HELLP syndrome and active lupus nephritis can be challenging, as they share common features like hypertension, proteinuria, hypoproteinemic edema, impaired renal function and thrombocytopenia; Also, pregnant women with SLE have a higher risk of preeclampsia compared to healthy pregnant women (27). Moreover, one feature may mask the other - active lupus nephritis in the first trimester of pregnancy make it difficult to diagnose preeclampsia later.
TABLE 3. Differential diagnosis between lupus nephritis and pre-eclampsia $(8,28-30)$

\begin{tabular}{|l|l|l|}
\hline & Related to pregnancy & Related to SLE flare \\
\hline Debut & After week 20 & During pregnancy \\
\hline $\begin{array}{l}\text { Arterial } \\
\text { hypertension / } \\
\text { proteinuria }\end{array}$ & yes & yes \\
\hline & & $\begin{array}{l}\text { Disease activity in } \\
\text { another organ }\end{array}$ \\
\hline C3, C4 & normal & low \\
\hline DsADN & Negative & high \\
\hline Liver enzymes & Normal/high & Normal/high \\
\hline $\begin{array}{l}\text { Resolves after } \\
\text { birth }\end{array}$ & Yes & no \\
\hline Urine & Proteinuria & $\begin{array}{l}\text { Proteinuria/Active } \\
\text { urinary sediment }\end{array}$ \\
\hline
\end{tabular}

When lupus nephritis flares, also the titer of anti dsDNA antibodies increases, the serum complement decreases, disease in other organs may flare, and the urinary sediment is active (28). The kidney biopsy may help to spot the active lupus nephritis, but the maneuver is associated with an increased risk in pregnant women.

\section{PREGNANCY MANAGEMENT IN SLE PATIENTS}

The EULAR (European League Against Rheumatism) and ACR (American College of Rheumatology) recommendations $(17,31)$ regarding pregnancy management in rheumatic inflammatory diseases are summarized in principles, as following:

- avoiding an unplanned pregnancy in order to enter pregnancy with low/no disease activity

- pre-pregnancy counseling

- switch to pregnancy-compatible medication use, if possible with enough time before pregnancy to assess the tolerability and efficacy of the new medication $(9,13)$

- concurrent care with a team of obstetrician / gynecologist, maternal-fetal medicine specialist and rheumatologist

- for pregnant patients with active disease, steroid -sparing or low dose steroid treatment is strongly recommended.

After assessing the disease activity, the next step in risk stratification is to evaluate the status of anti-Ro /SSA and anti-La/SSB antibodies, as well as APS specific antibodies (17). 
To conclude, pregnancy outcome in patients with SLE may be optimized by careful planning of the pregnancy and close follow-up of the mother and of the fetus.

\section{NEW-ONSET SLE WITH PREGNANCY}

In some patients, however, none of the above-mentioned precautions with respect to the pregnancy planning can be followed, as the onset of SLE can even occur during pregnancy. New-onset SLE with pregnancy is defined as the diagnosis of SLE being made when the patient is pregnant or in her puerperium (32). New-onset SLE is to be suspected and thorough check-up should be done as soon as possible when symptoms mimicking preeclampsia appear in the first or second trimester of pregnancy or persist after delivery (33).

Pregnancy-onset SLE is associated with more severe disease, renal and hematologic involvement and with worse maternal outcome than known SLE at pregnancy. However, fetal complications in new-onset patients may be the same as those of patients with an SLE history (33).

\section{CASES PRESENTATIONS}

During pregnancy, it is very challenging to diagnose the active new-onset SLE; However, severe flare was associated with pregnancy complications (1).

Herein we present two cases of SLE manifested by preeclampsia during labor considered as a complication of preeclampsia in two healthy women. A difficult diagnosis was made after a few months of worsening clinical situation.

\section{Case 1}

A 34-year-old primipara primigravida was admitted in spontaneous labor at 38 weeks of gestation. Her pregnancy was monitored uneventfully, and there was no significant personal or familial medical history. No abnormalities or fetal growth restriction were found in fetal screening ultrasounds. The patient was planned for a cesarean section based on her request. The blood tests performed on the morning of the same day (before cesarean section) were not known at the time of admission and during labor.

In the delivery room at admission, the patient was in the second stage of labor, with $7 \mathrm{~cm}$ of cervical dilatation and spontaneous contractions, the blood pressure was of 160/90 $\mathrm{mmHg}$ - the first episode of hypertension diagnosed in labor. Gestational hyper- tension was managed and controlled $<140 / 90 \mathrm{mmHg}$, with antihypertensive medication and the patient agreed to vaginal delivery. During the night shifts, the hospital could not perform laboratory tests at the time of the case. About 4 hours after admission she gave birth by cesarean section to an eutrophic fetus weighted 3,500 grams, Apgar score 10 at 1 and 5 minutes. Cesarean section was performed at full dilatation for non-engagement of the fetal head. The evolution in early the postoperative period is marked by the sudden appearance of renal insufficiency with creatinine values over $8 \mathrm{mg} / \mathrm{dl}$, by cardiorespiratory insufficiency, and the patient was admitted to the Intensive Care Unit with renal dialysis. The case was managed considering it a complication of preeclampsia; a severe clinical evolution was noted. A few months after birth, SLE is diagnosed, for which the specific treatment begins, the patient's condition improving. More than 1 year after birth, the patient is in remission and has a normal evolution, without sequelae.

\section{Case 2}

A 27-year-old primipara primigravida was admitted via the emergency department in the second stage of labor. At the emergency department, the patient complained about headache; the blood pressure was $160 / 90 \mathrm{~mm} \mathrm{Hg}$ and fetal bradycardia at 60 beats/min was diagnosed. In less than 5 minutes as she arrived in the labor room, no fetal heartbeats were recorded, and placental abruption were suspicioned. No prenatal tests or follow-up screening evaluation during pregnancy, she had only one ultrasound to check the fetal morphology. Her body mass index (BMI) was over 30 .

In the delivery room at admission, patient was in the second stage of labor, with $8 \mathrm{~cm}$ of cervical dilatation and spontaneous contractions, the blood pressure was 180/90 mm Hg. The blood pressure were difficult to maintain at $140 / 90 \mathrm{mmHg}$ with specific treatment. Blood tests at admission indicate hemoglobin level $(\mathrm{Hb})$, hematocrit $(\mathrm{Ht})$, platelets counts, hepatic transaminases (ALT, AST) within normal limits, normal fibrinogen level close to $500 \mathrm{mg} / \mathrm{dl}$. After artificial rupture the membranes, the amniotic fluid was clear and oxytocin was administered. The patient gave birth after 2 hours to a dead baby weighed 3,900 grams, normal placental delivery and the third stage of labor uneventful. Postpartum blood tests remain within normal limits, but about 8 hours after birth, a postpartum hemorrhage occurs, the patient enters the intravascular coagulation with fibrinogen consumption and renal failure, creatinine level 
attempt over $6 \mathrm{mg} / \mathrm{dl}$. Active management of uterine hemorrhage by iv replacements and control of the soft parts, the uterine cavity, massage and Oxytocin and Pabal administration lead to stop the hemorrhage. Uterus was well contracted. But in a few hours, anuria and acute and severe renal insufficiency occurred, with blood creatinine level increasing above $8 \mathrm{mg} / \mathrm{dl}$. The patient was transferred in forced transfer to an Intensive Care Unit with renal dialysis. The patient was dialyzed, and about 2 months after birth the diagnosis of SLE was established.

\section{DISCUSSION}

During pregnancy, most women are offered consultations with doctors, laboratory tests, prenatal screening by ultrasound, and specific laboratory tests. Before giving birth blood tests checking blood group, hemoglobin levels, coagulation blood tests are required by the anesthetist doctor. The cases was difficult to manage due to the fact that SLE was manifested by preeclampsia and severe renal insufficiency during the postpartum period. Severe disease flare is associated with pregnancy complications (22).

Conflict of interest: none declared

Financial support: none declared

\section{REFERENCES}

1. Buyon JP, Kim MY, Guerra MM, et al. Predictors of pregnancy outcomes in patients with lupus: A cohort study. Ann Intern Med. 2015;163(3):153-163.

2. Skorpen CG, Hoeltzenbein M, Tincani A, et al. The EULAR points to consider for use of antirheumatic drugs before pregnancy, and during pregnancy and lactation. Ann Rheum Dis. 2016;75(5):795-810.

3. Clowse MEB, Magder LS, Witter F, Petri M. The impact of increased lupus activity on obstetric outcomes. Arthritis Rheum. 2005;52(2):514-521

4. Mina R, Brunner HI. Pediatric Lupus-Are There Differences in Presentation, Genetics, Response to Therapy, and Damage Accrual Compared with Adult Lupus? Rheum Dis Clin North Am. 2010;36(1):53-80.

5. Clowse MEB. Lupus Activity in Pregnancy. Rheum Dis Clin North Am. 2007;33(2):237-252.

6. Tsuda S, Sameshima A, Sekine M, et al. Pre-conception status, obstetric outcome and use of medications during pregnancy of systemic lupus erythematosus (SLE), rheumatoid arthritis (RA) and inflammatory bowel disease (IBD) in Japan: Multi-center retrospective descriptive study. Mod Rheumatol. 2020;30(5):852-861.

7. Østensen M, Förger F, Villiger PM. Cytokines and pregnancy in rheumatic disease. In: Annals of the NewYork Academy Od Sciences. Vol 1069. Blackwell Publishing Inc.; 2006:353-363.

8. Daia-lliescu S. Sarcina si bolile reumatice. In: Ionescu R (ed.). Esentialul in reumatologie, Editia a 3-a. Ed. Amaltea, 2021.

9. Andreoli L, Fredi M, Nalli C, Reggia R, Lojacono A, Motta M, Tincani A. Pregnancy implications for systemic lupus erythematosus and the antiphospholipid syndrome. J Autoimmun. 2012 May;38(23):J197-208

10. Popescu MR, Dudu A, Jurcut C, Ciobanu AM, Zagrean AM, Panaitescu AM. A broader perspective on anti-Ro antibodies and their fetal consequences. A case report and literature review. Diagnostics. 2020;10(7).

11. Yasmeen S, Wilkins EE, Field NT, Sheikh RA, Gilbert WM. Pregnancy outcomes in women with systemic lupus erythematosus. J Matern Neonatal Med. 2001;10(2):91-96.
All the studies have demonstrated that predictors for fetal and maternal poor pregnancy outcomes in SLE are antiphospholipid antibodies, thrombocytopenia $<50 \times 109$ cells/l), history of lupus nephritis, hypertension, prednisone dose $>20 \mathrm{mg}$, and active lupus before and during pregnancy $(1,3,34)$. These two cases confirm that untreated SLE negatively affects kidney function, leading to serious complications associated with pregnancy-related hypertension, preeclampsia, and kidney failure. A systematic review and meta-analysis by $\mathrm{Wu}$ et al. 665 pregnant women with SLE demonstrated a significant association with gestational hypertension (OR 5.65), preeclampsia (OR 2.84), renal flare (OR 15.18), proteinuria $(\mathrm{OR}=8.86)$, and hypocomplementemia $(\mathrm{OR}=2.86)(35)$.

\section{CONCLUSION}

Pregnancy in patients with SLE remains a very high-risk pregnancy and a thorough clinical and immunological check-up is recommended in at risk female patients when planning the pregnancy.

12. Mehta B, Luo Y, Xu J, et al. Trends in maternal and fetal outcomes among pregnant women with systemic lupus erythematosus in the United States. Ann Intern Med. 2019;171(3):164-171.

13. Balanescu A, Parvu M. Lupusul eritematos sistemic si sarcina. In: Gheorghe Peltecu (coord.). Tratat de Chirurgie, vol V. Obstetrică şi Ginecologie. Editura Academiei Române, 2014:789-802.

14. Borella E, Lojacono A, Gatto M, et al. Predictors of maternal and fetal complications in SLE patients: a prospective study. Immunol Res. 2014;60(2-3):170-176.

15. Ko HS, Ahn HY, Jang DG, Choi SK, Park YG, Park IY, Lee G, Park SH, Shin JC. Pregnancy outcomes and appropriate timing of pregnancy in 183 pregnancies in Korean patients with SLE. Int J Med Sci. 2011;8(7):577-83.

16. Sammaritano LR, Bermas BL, Chakravarty EE, et al. 2020 American College of Rheumatology Guideline for the Management of Reproductive Health in Rheumatic and Musculoskeletal Diseases. Arthritis Rheumatol. 2020;72(4):529-556.

17. Sammaritano LR, Bermas BL, Chakravarty EE, et al. 2020 American College of Rheumatology Guideline for the Management of Reproductive Health in Rheumatic and Musculoskeletal Diseases. Arthritis Rheumatol. 2020;72(4):529-556.

18. Gayed M, Gordon C. Pregnancy and rheumatic diseases. Rheumatology. 2007;46(11):1634-1640.

19. George S, Alan NB. Flares of Systemic Lupus Erythematosus During Pregnancy and the Puerperium. Available at: https://www. medscape.org/viewarticle/768080_1.

20. Kwok LW, Tam LS, Zhu TY, Leung YY, Li EK. Predictors of maternal and fetal outcomes in pregnancies of patients with systemic lupus erythematosus. Lupus. 2011;20(8):829-836.

21. Madazli R, Bulut B, Erenel H, Gezer A, Guralp O. Systemic lupus erythematosus and pregnancy. J Obstet Gynaecol (Lahore). 2010;30(1):17-20.

22. Davis-Porada J, Kim MY, Guerra MM, et al. Low frequency of flares during pregnancy and post-partum in stable lupus patients. Arthritis Res Ther. 2020;22(1):52 
23. Ruiz-Irastorza G, Lima F, Alves J, Khamashta MA, Simpson J, Hughes GR, Buchanan NM. Increased rate of lupus flare during pregnancy and the puerperium: a prospective study of 78 pregnancies. Br J Rheumatol. 1996 Feb;35(2):133-8.

24. Saulescu I. Agenti biologici utilizati in LES in terapia biologica in bolile inflamatorii reumatice ale adultului. Ionescu R, Opris-Belinski D (eds.). Editura Medicala, Bucuresti; 2019.

25. Buyon JP, Kalunian KC, Ramsey-Goldman R, et al. Assessing disease activity in SLE patients during pregnancy. Lupus. 1999;8(8):677-684.

26. Lai J, Syngelaki A, Nicolaides KH, von Dadelszen P, Magee LA. Impact of new definitions of preeclampsia at term on identification of adverse maternal and perinatal outcomes. Am J Obstet Gynecol. 2021;224(5):518.e1-518.e11.

27. Dong Y, Yuan F, Dai Z, Wang Z, Zhu Y, Wang B. Preeclampsia in systemic lupus erythematosus pregnancy: a systematic review and meta-analysis. Clin Rheumatol. 2020;39(2):319-325.

28. Knight CL, Nelson-Piercy C. Management of systemic lupus erythematosus during pregnancy: Challenges and solutions. Open Access Rheumatol Res Rev. 2017;9:37-53.

29. Bermas LB, O'Del J, Lockwood JC. Rheumatoid arthritis and pregnancy. Available at: https://www.uptodate.com/contents/ rheumatoid-arthritis-and-pregnancy?source=history_widget.
30. El Miedany Y, Palmer D. Rheumatology-led pregnancy clinic: enhancing the care of women with rheumatic diseases during pregnancy. Clin Rheumatol. 2020;39(12):3593-3601.

31. Andreoli L, Bertsias GK, Agmon-Levin N, et al. EULAR recommendations for women's health and the management of family planning, assisted reproduction, pregnancy and menopause in patients with systemic lupus erythematosus and/or antiphospholipid syndrome. Ann Rheum Dis. 2017;76(3):476-485.

32. He X, Jiang D, Wang Z, et al. Clinical features of new-onset systemic lupus erythematosus during pregnancy in Central China: a retrospective study of 68 pregnancies. Clin Rheumatol. 2021;40(6):2121-2131.

33. Zhao C, Zhao J, Huang Y, et al. New-onset systemic lupus erythematosus during pregnancy. Clin Rheumatol. 2013;32(6):815822.

34. Cortes-Hernandez J, Ordi-Ros J, Paredes F, Casellas M, Castillo F, Vilardell-Tarres M. Clinical predictors of fetal and maternal outcome in systemic lupus erythematosus: A prospective study of 103 pregnancies. Rheumatology. 2002;41(6):643-650.

35. Wu J, Ma J, Zhang WH, Di W. Management and outcomes of pregnancy with or without lupus nephritis: A systematic review and meta-analysis. Ther Clin Risk Manag. 2018;14:885-901. 